\title{
Computational Performance Assessment of Damaged RC Members with Fractured Stirrups
}

\author{
Kukrit Toongoenthong ${ }^{1}$ and Koichi Maekawa ${ }^{2}$
}

Received 3 August 2004, accepted 24 September 2004

\begin{abstract}
The mechanical effect of fractured web reinforcement on structural safety was experimentally investigated by intentionally avoiding hooks or anchorage devices at the extreme ends of stirrups, which were replicas of web steel damaged by corrosion or alkali-aggregate reaction of concrete. Significant reduction in shear capacity was experimentally found without yielding of web reinforcement when the web steel anchorage was incomplete. A marked difference in failure crack patterns was also observed compared with the sound RC specimen. Longitudinal cracks were ultimately formed along the main reinforcement where the unprocessed edges of the stirrups lie. Non-linear finite element analysis was employed to investigate and simulate failure processes and static capacity. The bond deterioration zone of the web reinforcement was computationally assumed to be ten times the diameter of steel bars from the cut-off trimming of steel bars. This simple assumption in nonlinear computation was verified to be acceptable for performance assessment of damaged reinforced concrete with fractured stirrups.
\end{abstract}

\section{Introduction}

Practitioners in charge of infrastructure maintenance and management are currently facing serious questions on the remaining functionality of reinforced concrete damaged by weathering. A computational approach to assessing RC structural safety performance over the service life has been proposed (Maekawa and Chaube 1999 and Maekawa et al. 2003a), and pre-existing cracks in structural concrete have been discussed from the prospective of nonlinear mechanics. Inevitably, real RC structures subjected to multiple forms of environmental risks such as corrosion and alkali aggregate reaction of concrete to a greater or lesser degree, and the resulting damage in reinforcement as well as concrete needs to taken into consideration.

It is well known that chloride ingress and/or carbonation raise the risk of reinforcement corrosion, which has much to do with the alkalinity of the original concrete cover. Steel corrosion results in loss of reinforcement sections and ultimately in the rupture of steel, especially at the bent portions. Moreover, in the case of the alkali aggregate reaction, the volumetric expansion of gel products around active aggregates may induce cracking in structural concrete as well as excessive extension of reinforcement. Such volumetric expansion is prevented or retarded through confinement of concrete by steel reinforcement.

It was reported for some bridge piers in Japan that the

${ }^{1}$ Post Doctoral Fellow, Department of Civil Engineering The University of Tokyo, Tokyo, Japan.

Email: kukrit1@concrete.t.u-tokyo.ac.jp

${ }^{2}$ Professor, Department of Civil Engineering, The University of Tokyo, Tokyo, Japan. confinement of volumetric expansion caused by the alkali aggregate reaction may lead to complete rupture at bent portions of stirrup steels and main longitudinal reinforcement at the anchorage zone, and welding points (Miyagawa 2003), as shown in Fig. 1. This failure raises questions about the safety of such a damaged RC structure. The observed declines in anchorage capacity and their performance against external shear have been deemed to not satisfy the required structural performance, and are being urgently investigated to obtain a reliable safety assessment method and repair in line with maintenance planning.

In this paper, the authors investigate the influence of broken web reinforcement on overall member performances by conducting an experimental program on defective stirrups for RC beams under static loads. A numerical analysis method is also applied for safety performance assessment of steel fractured RC members in shear and experimentally verified for accuracy and applicability. As non-orthogonal crack intersections in concrete may occur under combined mechanical forces and environmental actions, multi-directional non-orthogonal fixed crack modeling for concrete is applied. In this study, non-damaged sound concrete is experimentally reproduced in order to focus on the effect of premature anchorage at the extreme ends of reinforcing bars. Thus, the coupling of broken reinforcement with damaged concrete will be subsequently investigated in future.

\section{Experimental program}

\subsection{Specimen and materials}

For evaluating the effect of broken stirrups in RC beams on their shear capacity and ductility (see Fig. 1), an experimental program of RC beams with shear reinforcement, whose anchorage and bond were removed, was 
conducted. Figure 2 shows the specimen details and reinforcement arrangement. The shear-span to depth ratio denoted by a/d was 3.2 with a tension reinforcement ratio of $1.46 \%$ and the anchorage length of the main tensile reinforcement was $0.2 \mathrm{~m}$. The shear reinforcement ratio was $0.226 \%$ with a spacing of $0.1 \mathrm{~m}$ as shown in Fig. 2. The concrete cover of the stirrup was $22 \mathrm{~mm}$. The tested compressive strength of the concrete after standard curing of 28 days was $35 \mathrm{MPa}$. The high yield strength of both the tension and compression reinforcement was $645 \mathrm{MPa}$ for producing a comparatively large flexural capacity to ensure that shear failure would occur. The yield strength of the shear reinforcement was $345 \mathrm{MPa}$. The loading was applied with combined flexure-shear forces. The loading mode was static at the middle of the beams. The rate of displacement at the loading point was controlled to be $0.2 \mathrm{~mm} /$ minute in all cases. The width and thickness of loading and support steel plates was $100 \mathrm{~mm}$ and $10 \mathrm{~mm}$ respectively.

This setup was designed as an analogy of corroded broken web reinforcement or ruptured stirrups at bent portions caused by the alkali aggregate reaction. The legs of shear stirrups near the tensile reinforcement were unprocessed without curved hook fabrication before concrete placement. Premature anchorage of web steel is thought to cause degradation of reinforcement capability and the loss of bond close to the tip of cut-off steel may occur as a result. In the case of a smaller shear span to depth ratio, insufficient anchorage of stirrups would not change the load carrying mechanism of the concrete to a considerable degree, because the so-called tied-arch mechanism is essentially formed regardless of the amount of web reinforcement. Thus, the authors did not use deep beams in the experimental program but selected instead a slender shape of $\mathrm{a} / \mathrm{d}=3.2$ with a comparatively larger amount of stirrups.

The difference in surface condition at the legs of stirrups was additionally addressed for each side of the beam by wrapping the extreme ends of stirrup-legs with a $5 \mathrm{~cm}$ long strip of vinyl tape (see Fig. 2). The aim of the vinyl tape wrapping was to create smooth surfaces for eliminating bond close to the edge positions. The moment capacity of the non-damaged referential beam was computed by employing the material properties and

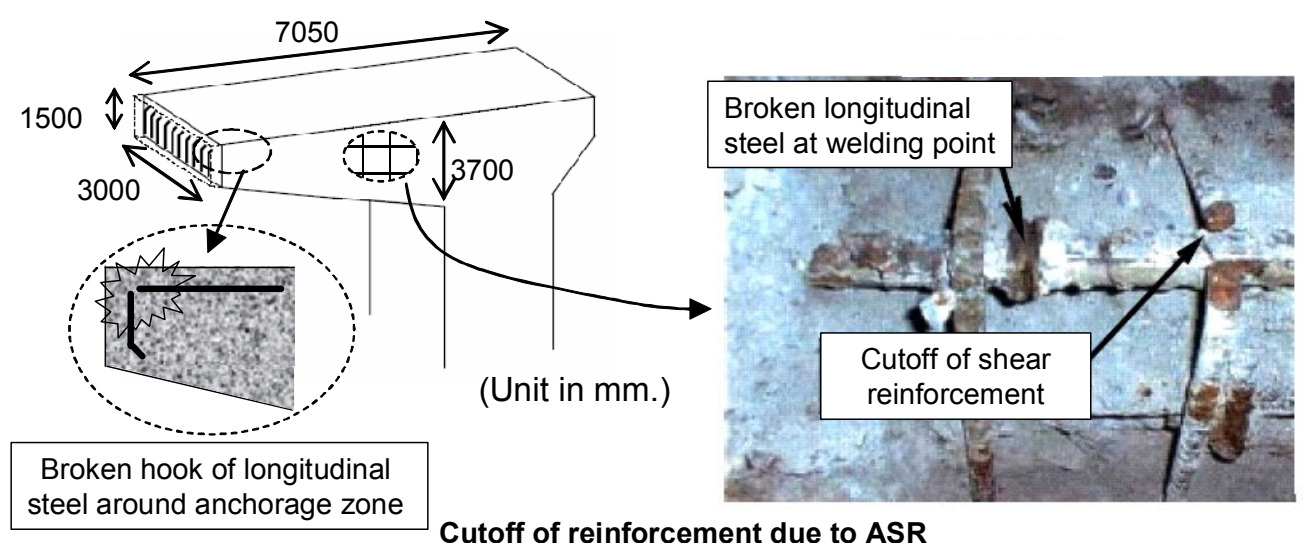

Fig. 1 Broken web reinforcement found in the real RC structures (Miyagawa 2003).

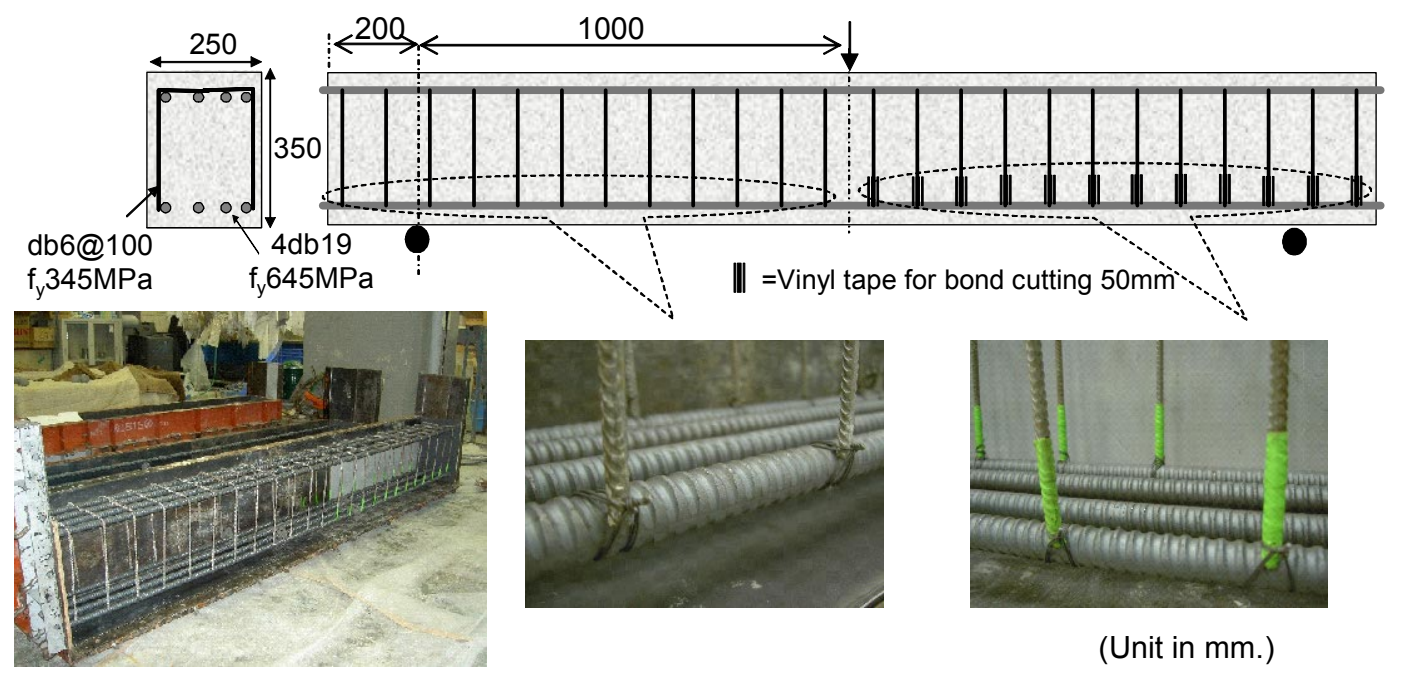

Fig. 2 Specimen setup, dimension and reinforcement arrangement. 
detailed geometry of the cross section. The shear capacity was predicted based on the JSCE standard specification (JSCE 2002, Okamura and Higai 1980). The sectional capacity of the non-damaged referential beam is shown in Table 1. A non-damaged referential beam was also produced with standardized hooks of stirrups according to the provisional structural details in design

Table 1 Calculated bending and shear capacity.

\begin{tabular}{|c|c|}
\hline Properties & Values \\
\hline shear span: effective depth $(\mathrm{a} / \mathrm{d}$ ratio $)$ & 3.2 \\
\hline $\begin{array}{c}\text { Shear capacity of concrete }\left(\mathrm{V}_{\mathrm{c}}\right) \\
\text { Okamura-Higai equation }\end{array}$ & $90.7 \mathrm{kN}$ \\
\hline Shear capacity of Stirrups $\left(\mathrm{V}_{\mathrm{s}}\right)$ & $60.5 \mathrm{kN}$ \\
\hline Yielding Moment Capacity $\left(\mathrm{M}_{\mathrm{y}}\right)$ & $202.9 \mathrm{kN}-\mathrm{m}$ \\
\hline Bending Failure Load $\left(\mathrm{P}_{\mathrm{y}}\right)$ & $405.8 \mathrm{kN}$ \\
\hline Shear Failure Load $\left(\mathrm{P}_{\mathrm{v}}\right)$ & $302.4 \mathrm{kN}$ \\
\hline
\end{tabular}

Note: $V_{c}$ by JSCE 2002 (Okamura and Higai)

$$
\begin{aligned}
V_{c} & =\beta_{d} \cdot \beta_{p} \cdot f_{v c d} \cdot b_{w} \cdot d \\
\beta_{d} & =\sqrt[4]{1 / d} \leq 1.5(\mathrm{~d}: \mathrm{m}) \\
\beta_{p} & =\sqrt[3]{100 p} \leq 1.5 \\
f_{v c d} & =0.2 \sqrt[3]{f_{c}^{\prime}} \leq 0.72\left(\mathrm{~N} / \mathrm{mm}^{2}\right)
\end{aligned}
$$

$\mathrm{d}$ : effective depth, $\mathrm{p}$ : longitudinal steel ratio $f_{c}{ }^{\prime}$ : design concrete compressive strength $\mathrm{b}_{\mathrm{w}}$ : web width

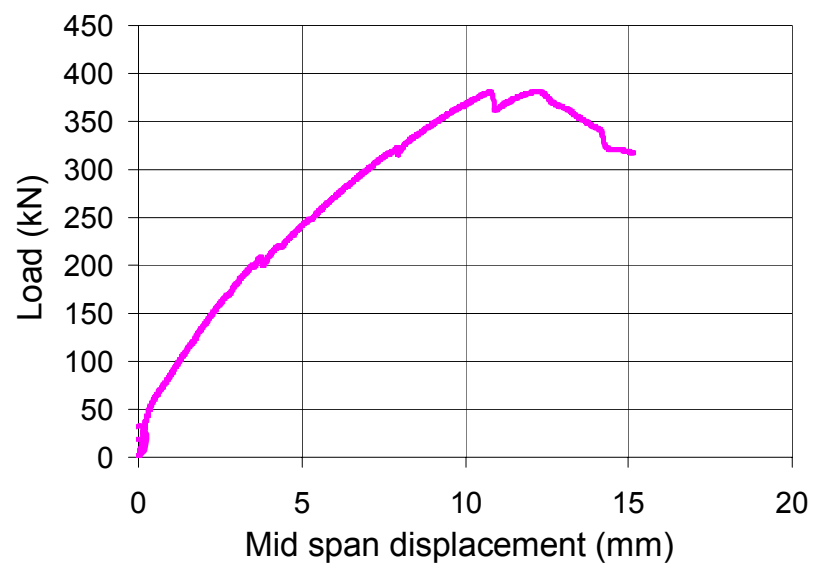

a) Load-deflection response codes.

It should be noticed that the RC beam specimen was fabricated by providing $0.2 \mathrm{~m}$ anchorage length without hook of main reinforcement around anchorage zone, which obviously violated the general specified codes. This condition of anchorage was intended to represent the damage of the bar hook at the member's ends (leaving the risk of insufficient development length of anchorage main steel) as found in the ASR damaged structure as seen in Fig.1. As a matter of fact, the problem of fractured shear reinforcements and effect on shear capacity is the main discussing point in this paper. Hence, although an anchorage design code was not satisfied, the existing anchorage length was proved to be sufficient to avoid the anchorage failure in the referential non-damaged beam as shown experimentally and numerically in the latter parts. The problem of critical damage condition around anchorage zone due to ASR or reinforcement corrosion was investigated and discussed in the relevant paper (Toongoenthong and Maekawa, 2004).

\subsection{Loading test results}

Figure 3a shows the load-deflection relation at the midspan of the non-damaged beam. The load-deflection relationship indicates the change in stiffness approximately at the load level of $200 \mathrm{kN}$, which is close to the computed concrete shear capacity without web reinforcement. In reality, diagonal shear cracking was initi-

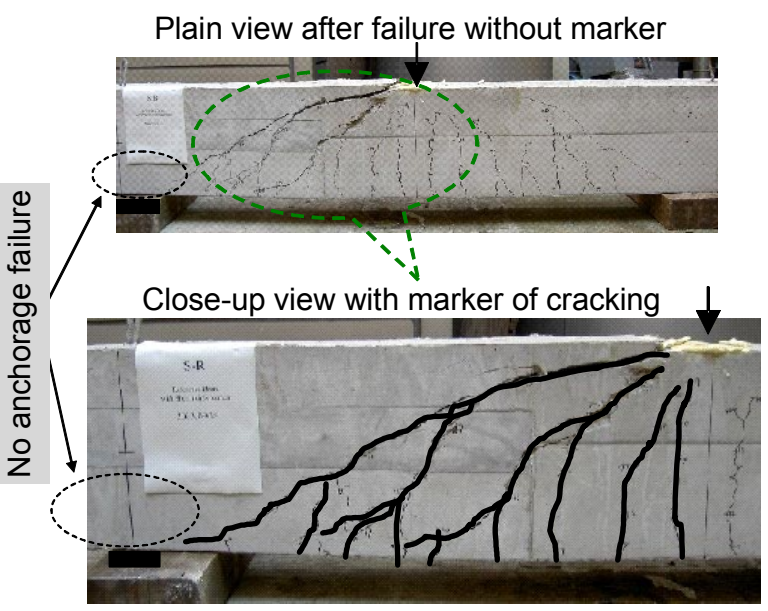

b) Failure crack pattern

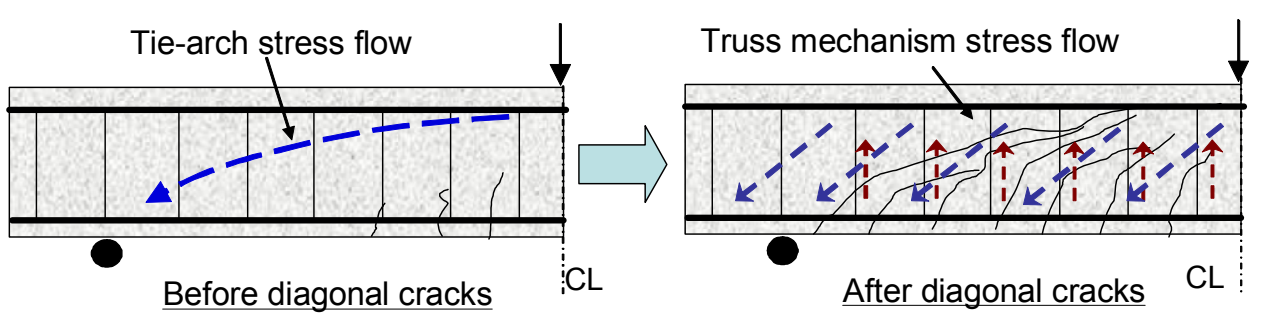

c) Shear resisting truss-mechanism in non-damaged beam

Fig. 3 Experimental result of non-damaged beam: reference case. 
ated in the web. After the first diagonal shear crack, somewhat dispersed diagonal cracks were formed owing to spatially dispersed shear reinforcement. The final failure stage was then reached with the formation of an unstable shear failure path between the loading point and the beam supports. This resulted in a permanent decrease in the load-carrying mechanism.

The shear capacity at the peak was approximately 380 $\mathrm{kN}$, which coincides fairly well with the shear strength computed by the JSCE standard specification (JSCE 2002, Okamura et al. 1980) taken into consideration the fact that the computed shear capacity corresponds to the yield limit state of web steel. It is important to note that the shear force carried by concrete is approximately $53 \%$ of the total shear capacity. This means that the contribution of web reinforcement is not less than in the case of large-scale bridge infrastructures currently in service. The experimental crack pattern after failure is also shown in Fig. 3b, which indicates dispersed diagonal shear cracks. When the beam experienced its peak capacity, the main reinforcement remained elastic. A decline in residual force was evidenced with a localized band of shear deformation in the web concrete after the peak.

After the reference case was reviewed, the RC beam with built-in damage in shear reinforcement was loaded. As mentioned earlier, this damaged beam was intentionally given imperfections by straight cut-off of the stirrup legs close to the tensile reinforcement as shown in Fig.
2. Since the unprocessed edge of the shear reinforcement was made before concrete casting, the local interfacial condition between the stirrups and surrounding concrete was expected to be sufficiently maintained even for the broken stirrups. Figure 4a shows the experimental load-deflection curve of the damaged beam exhibiting shear failure in the shear span containing the broken web reinforcement. A significant reduction in shear capacity can be clearly seen. The damaged beam containing cut-off shear reinforcement reached the ultimate capacity of $240 \mathrm{kN}$, which is a decrease in shear of approximately $37 \%$ compared with the non-damaged reference.

The different crack pattern of the insufficient anchored stirrup was also prominently observed at failure (see Fig. 4b). Starting with a set of flexural cracks denoted by No. 1 in the figure, we can observe propagation and varying crack angles at the higher loads that form the diagonal shear cracks around the web (crack set indicated by No. 2 in Fig. 4b). Without straight cutoff of the stirrup legs, further development of distributed diagonal shear cracks can be expected for the nondamaged referential beam.

However, because of the discontinuity of the shear reinforcement legs adjacent to the longitudinal steels, sufficient anchorage does not develop but results in localized diagonal shear cracks (cracks indicated by No. 3 in Fig. 4b). As soon as the localized diagonal shear cracks are formed, highly stress concentration at the straight

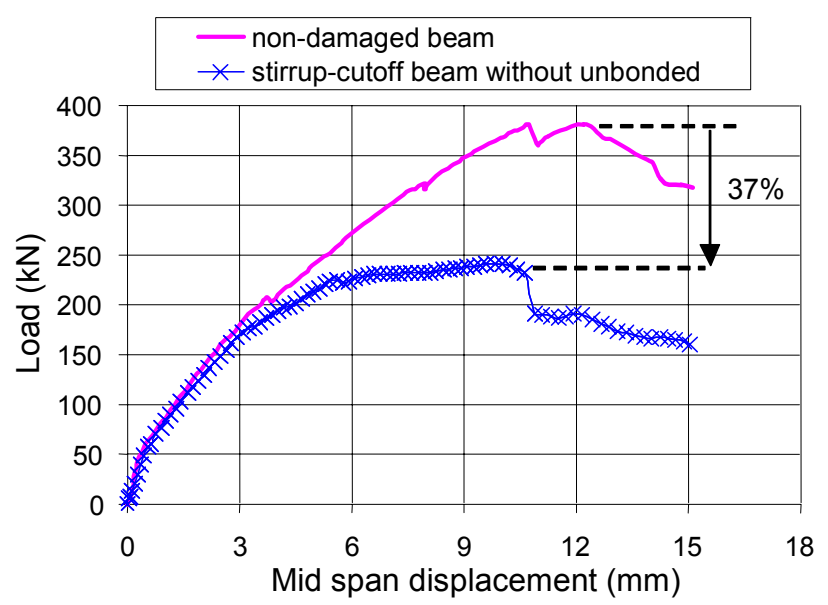

a) Load-deflection response

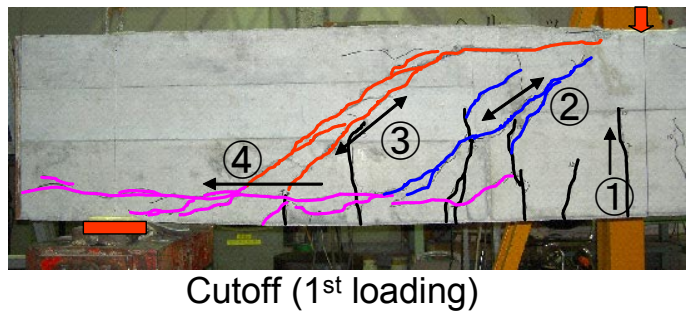

$\begin{array}{lll}\text { Cracking sequence } \rightarrow & \text { (1) (2), (3) (4) }\end{array}$ b) Failure crack pattern

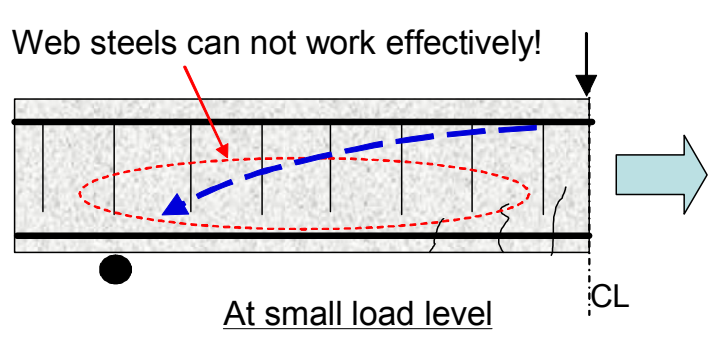

c) Risk of anchorage failure in fractured web beam

Fig. 4 Experimental result of beam with broken stirrup without bond cut-off. 
edge of stirrups close to the tensile reinforcement causes horizontal cracks penetrating along the tensile reinforcement (longitudinal cracks indicated by No.4 in Fig. 4b). It seems that the web steel may not resist crack propagation around its straight edge. This crack finally reached the anchorage zone of the main tensile reinforcement ahead of the beam support. At this moment, the stirrups could not effectively carry the tensile force and the peak capacity was reached. Here, the truss mechanism is thought to decline and is replaced with the tied arch system as shown in Fig. 4c. As a result, the resultant higher internal compression can flow to the anchorage zone for main reinforcement. Gradual decay of the residual force occurred in the post-peak region, as shown in Fig. 4a. Here, the deterioration in efficiency of the shear reinforcements was experimentally seen with no yielding of fractured stirrups.

After the failure of the damaged beam, which nevertheless maintained the local bond, strengthening was performed by encasing the failed shear span with ductile non-metallic sheets (Igarashi 2002) in order to subsequently apply the reloading on the other alive side of the beam. Here, imperfection of steel-concrete bondage near the edge of the stirrups may exist. As mentioned previously, a $5 \mathrm{~cm}$ long portion of the shear reinforcement legs from the extreme edge of the cut-off point (close to the tensile reinforcement) was wrapped with vinyl tape during the reinforcement fabrication so as to achieve a smooth surface representing the absence of bond, as shown in Fig. 2. The load-deflection relation of the beam with broken shear reinforcement and erased bond is shown in Fig. 5a. The shear capacity in this case was approximately $237 \mathrm{kN}$, which is nearly the same as the previous case where the monolithic steel-concrete bondage was retained, and represents a reduction in shear capacity of approximately $37 \%$ compared with the non-damaged reference.

Nevertheless, a sharp drop in residual capacity after the peak was observed in this case of perfect un-bonded stirrups at the extreme ends. This sudden drop in residual capacity is rooted in the complete loss of stress transfer between steel and concrete at the anchorage zone of web stirrups. Figure $\mathbf{5 b}$ also shows the failure crack pattern of the case where a partially unbonded stirrup was applied, which indicates a similar crack sequence and pattern as in the previous damaged beam. The less dispersed diagonal shear cracks developed due to insufficient bond and anchorage. Longitudinal splitting cracks along the tensile reinforcement were similarly observed prior to and after the peak capacity. They also invaded the anchorage zone of longitudinal reinforcement.

\section{Nonlinear analysis for RC members with fractured stirrups}

\subsection{Bond deterioration zone}

It was clarified and confirmed that shear reinforcement cannot fully work satisfactorily without hooks of web steel. In other words, full efficiency of the truss mecha-

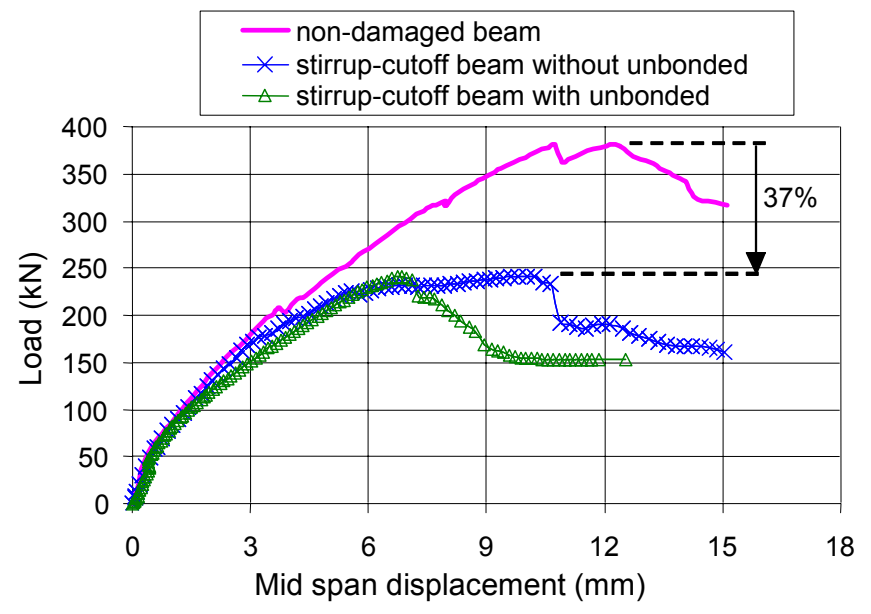

a) Load-deflection response

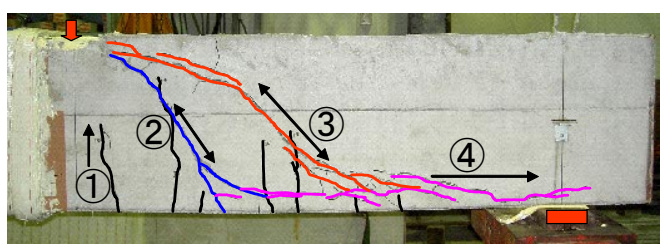

Cutoff ( $2^{\text {nd }}$ loading; after strengthening)

Cracking sequence $\rightarrow$ (1), 2), (3), (4)

b) Failure crack pattern

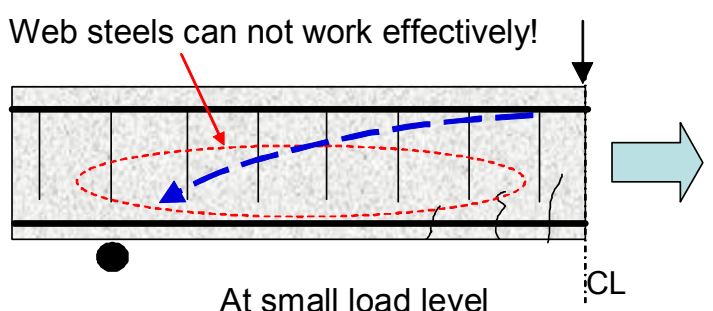

c) Risk of anchorage failure in fractured web beam

Fig. 5 Experimental result of the beam of broken stirrups with erased bond.

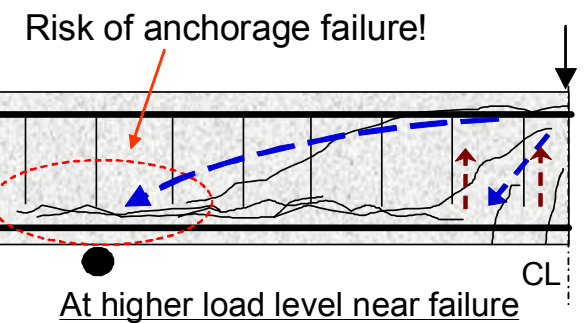


nism cannot be expected due to insufficient anchorage of shear reinforcement. As observed in the experimental crack pattern of the previous section, the occurrence of localized longitudinal cracks along the tensile reinforcement was seen at the straight edge location of the web reinforcement. In this section, the responses of $\mathrm{RC}$ members with fractured stirrups will be focused on for safety performance assessment using a nonlinear analysis. In order to investigate the failure process, a 2D nonlinear RC model with multi-directional fixed crack modeling (Maekawa et al. 2003b) will be employed hereafter. Although the nonlinearity of concrete compression softening and reinforcement post yielding can be considered in the model, their actual contribution to the ultimate capacity of experimented defective beam was very small in both analysis and experiment (no concrete compression softening and yielding of reinforcement).

Starting with the reference case of no-damage, we have the analytical results, which match fairly well both the experimental capacity and the cracking pattern. Figure 6a shows the load-deflection relation of the reference case with specified hooks. Distributed diagonal shear cracks can be simulated well owing to the existence of web reinforcement as shown in Fig. 6b. Here, the stirrup was numerically confirmed to have an effi-

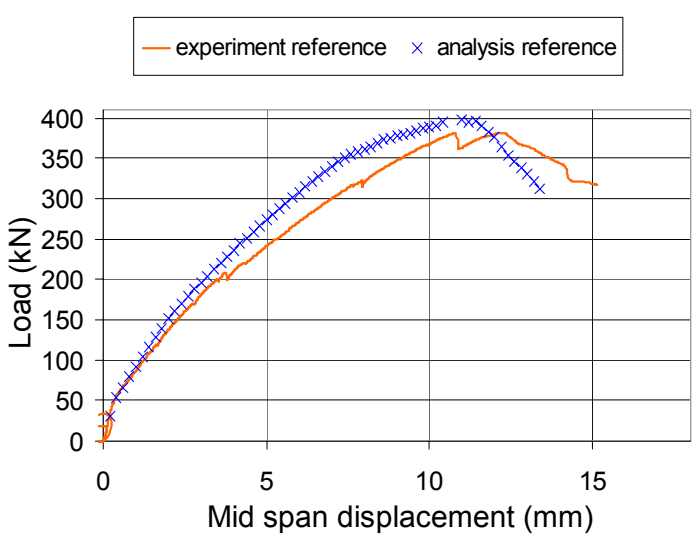

a) Load-deflection response

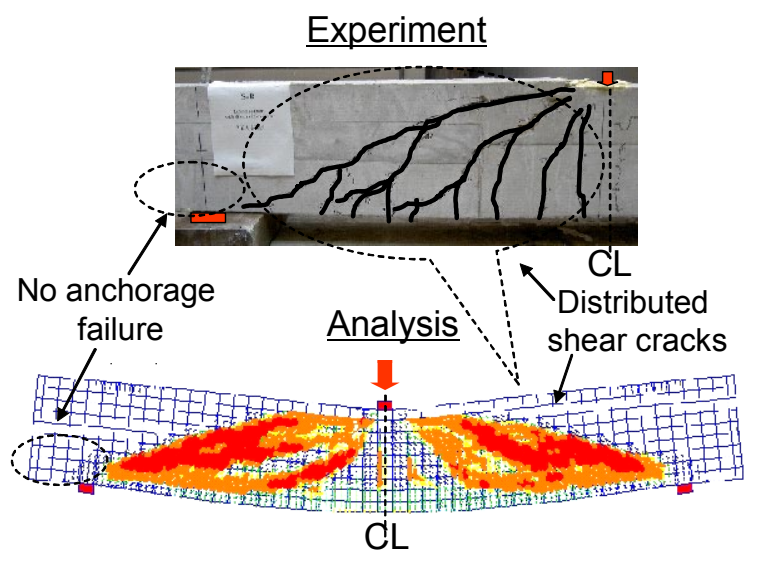

b) Failure crack pattern
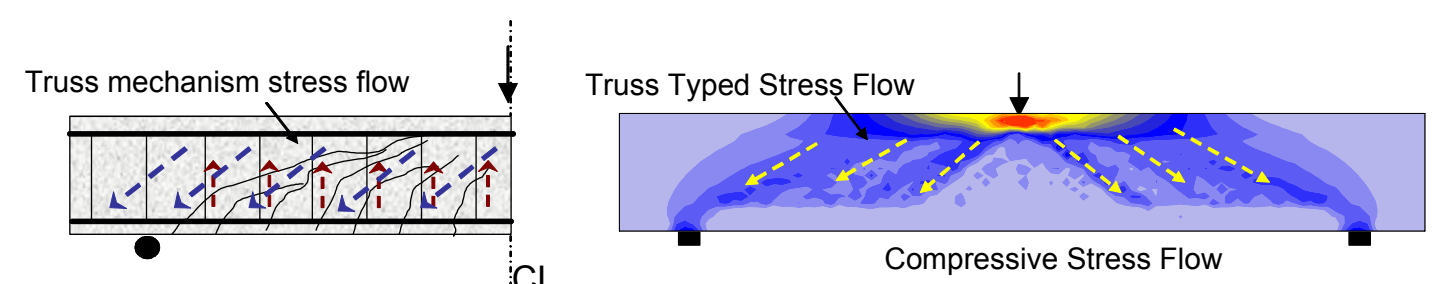

c) Stress transfer in non-damaged beam

Fig. 6 Load displacement relation and crack pattern of non-damaged beam.

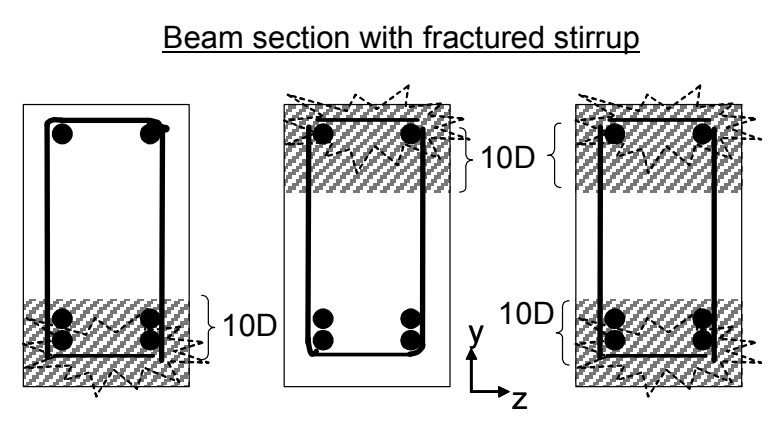

$10 \mathrm{D}=$ assumed bond deterioration zone

$$
\text { Zש }=\rho_{y}=\text { null (D: steel diameter) }
$$

Fig. 7 Assumed bond deterioration zone for fractured web reinforcement.

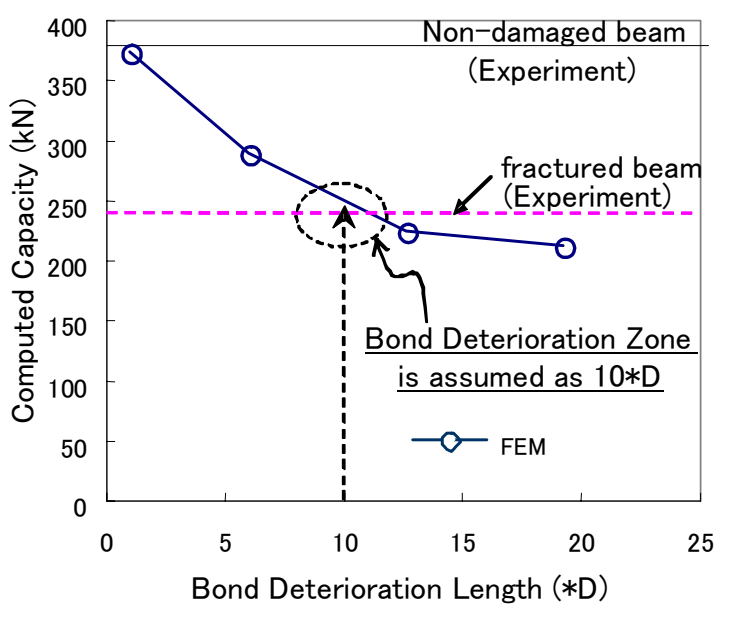


ciency similar to the experimental result. The truss-like stress flow of structural concrete compression can be also validated over the shear span as shown in Fig. 6c.

Next, the damaged RC beam without hooks of stirrups was computationally investigated. Bond deterioration was assumed to take into account the insufficient anchorage capability. No axial tensile stiffness of steel was assumed in the area of bond deterioration length. The numerical sensitivity analysis by non-linear FEM was performed beforehand by varying the size of the bond deterioration zone around the cut-off location near tensile reinforcements, as shown in Fig. $\mathbf{7 b}$ to obtain the overview of the bond damage associated with the nonhooked stirrups. Consequently, it can be said from the numerical results that bond deterioration can be specified at the extreme end of steel bars of 10 times diameter (10D) by assuming null steel tensile stiffness.

This means that the web reinforcement does not function anymore in this zone even if cracking may occur herein. The schematic representation of the possible

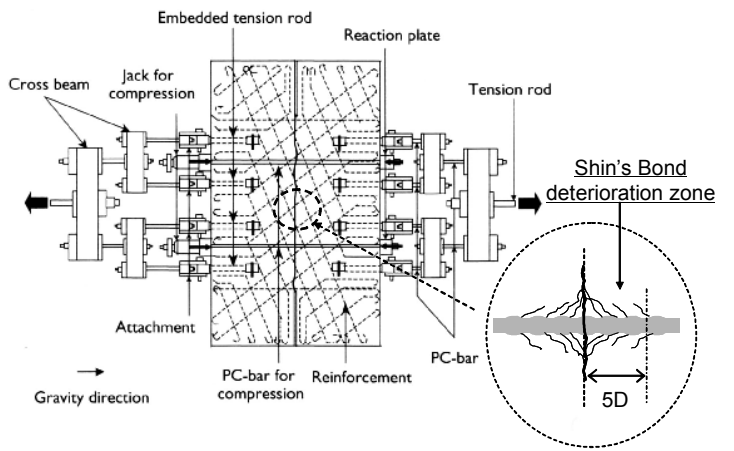

a) Experimental verification and bond deterioration zone assumed bond deterioration zone is shown in Fig. 7a, with expected variations in damage locations in reality. Figure 9a shows the numerical results of the damaged beam with unhooked shear reinforcement by applying this rule of the $10 \mathrm{D}$ deterioration size of bond. It can be seen that a reasonable numerical result can be obtained based on this simple assumption. It is concluded from the analysis that the truss-system by shear reinforcement is mechanically spoilt and that part of the functionality is lost due to incomplete anchorage of stirrups. Here, a tied-arch action subsequently occurred due to the bond deterioration formed along the longitudinal reinforcement (Toongoenthong and Maekawa 2004). This tiedarch stress flow of concrete can be clearly seen in Fig. 9b. Accordingly, the overload of the anchorage zone for longitudinal reinforcement became increasingly significant and finally failure reached this anchorage beyond the beam support as observed in both experiment and analysis (see Fig. 9b).

The assumed bond deterioration zone of 10 times di-

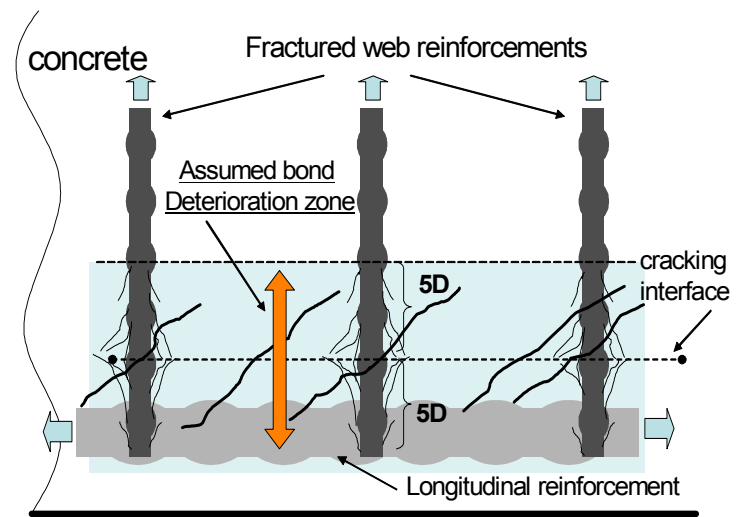

b) Assumed bond deterioration at bent portion of fractured web reinforcement

Fig. 8 Assumed bond deterioration zone considering the microscopic damage near the crack interface.

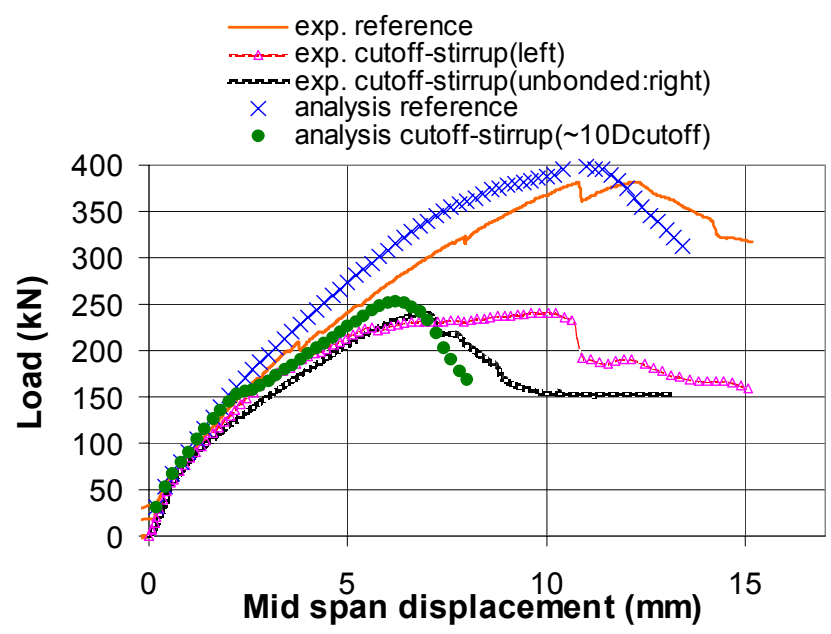

a) Load-deflection response

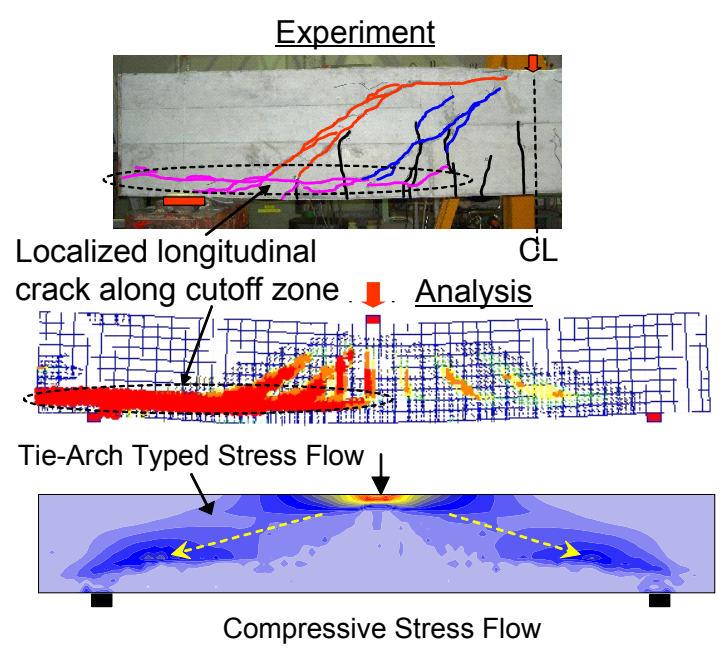

b) Failure crack pattern

Fig. 9 Load-displacement relation and crack pattern for cut-off stirrup beam. 
ameter is not merely an priori hypothesis but is also rooted in the microscopic interaction mechanics of the concrete crack plane and intersecting reinforcement. To take into account the discrete joint interface problems such as pull-out of anchored reinforcing bars from a footing, Mishima et al. (1992) enhanced the original Shima's model (1987) by incorporating the bond deterioration zone with the local bond-slip-strain model. In this model of RC joint interface, bond deterioration was assumed at a distance of five times diameter (5D) from the concrete crack plane. The model was then experimentally verified by using RC plate specimens with a single crack plane as shown in Fig. 8a. Here, it should be noted that sound condition of surrounding concrete close to a crack interface was maintained.

However, in the case of fractured web reinforcement by ASR near the bent portions (equivalent to unhooked stirrups), the soundness of the concrete around the fractured steel may not always be guaranteed. Figure $\mathbf{8 b}$ shows the schematic image of the cracking damage near the ruptured stirrups. In consideration of this damage at the fractured stirrup leg, it can be said that the bond deterioration zone of 10 times diameter of web reinforcement is practically reasonable from a microscopic viewpoint of bond deterioration.

\subsection{Experimental verification - Regan and Kennedy -}

In order to examine the applicability of the proposed modeling on bond deterioration of unhooked web reinforcement, further analyses were carried out. Experimental results by Regan and Kennedy (2004) on shear strength of RC beams with defective stirrup anchorages were used for experimental verification. The experiment was composed of thirteen RC beams arranged in four groups by varying reinforcement arrangement, effective depth and dimensions. Table 2 shows the material properties and details of defective stirrups (Regan and Kennedy 2004). Figures 10, 11, 12 and $\mathbf{1 3}$ show the specimen setup and dimensions of all four groups. Defective

Table 2 Comparison of experimental and analysis result with assumed bond deterioration.

\begin{tabular}{|c|c|c|c|c|c|c|c|c|c|c|c|}
\hline Group & $\begin{array}{c}\text { Beam } \\
\text { No. }\end{array}$ & $\begin{array}{c}\mathrm{d} \\
(\mathrm{mm})\end{array}$ & $\begin{array}{l}\text { concrete } \\
\mathrm{f}^{\prime} \mathrm{c}(\mathrm{Mpa})\end{array}$ & \begin{tabular}{|c|} 
\%Stirrup \\
Defective
\end{tabular} & $\begin{array}{l}\text { Cover of } \\
\text { Main } \\
\text { Tensile } \\
\text { Bars }\end{array}$ & $\begin{array}{c}\text { Experiment } \\
\text { Ultimate } \\
\text { Capacity } \\
\text { (kN) }\end{array}$ & $\begin{array}{c}\text { Analysis } \\
\text { Ultimate } \\
\text { Capacity } \\
\text { (kN) }\end{array}$ & $\begin{array}{c}\text { Capacity } \\
\text { Ratio } \\
\text { (FEM/Exp.) }\end{array}$ & $\begin{array}{l}V_{c} \text { by } \\
\text { JSCE } \\
\text { code }\end{array}$ & $V_{s} / V_{c}$ & FailureMode \\
\hline \multirow{4}{*}{ A. } & 1 & \multirow{4}{*}{335} & 58.1 & - & $\mathrm{Y}$ & 314 & 320 & 1.02 & 78.1 & 0.89 & Bending \\
\hline & 2 & & 56.6 & 75 & $Y$ & 310 & 313 & 1.01 & 77.45 & 0.91 & Bending \\
\hline & 3 & & 60.2 & 50 & $Y$ & 314 & 315 & 1.00 & 79.05 & 0.89 & Bending \\
\hline & 4 & & 52.8 & 50 & $Y$ & 314 & 316 & 1.01 & 75.65 & 0.93 & Bending \\
\hline \multirow{2}{*}{ B. } & 5 & \multirow{2}{*}{350} & 51.9 & - & $\bar{Y}$ & 250 & 265 & 1.06 & 77.45 & 0.46 & Shear \\
\hline & 6 & & 43.8 & 75 & $Y$ & 210 & 219 & 1.04 & 73.47 & 0.48 & Shear \\
\hline \multirow{4}{*}{ C. } & 7 & \multirow{4}{*}{340} & 47.3 & - & $\bar{Y}$ & 414 & 424 & 1.02 & 81.94 & 0.97 & Shear \\
\hline & 8 & & 53.3 & 67 & $Y$ & 340 & 369 & 1.09 & 85.26 & 0.93 & Shear \\
\hline & 9 & & 45 & 67 & $\mathrm{~N}$ & 330 & 364 & 1.10 & 80.59 & 0.99 & Shear \\
\hline & 10 & & 49.7 & 67 & $\mathrm{~N}$ & 280 & 359 & 1.28 & 83.3 & 0.96 & Shear \\
\hline \multirow{3}{*}{ D. } & 11 & \multirow{3}{*}{200} & 47.5 & - & $\bar{Y}$ & 252 & 258 & 1.02 & 54.75 & 0.91 & Shear \\
\hline & 12 & & 47.5 & No Stirrup & $Y$ & 100 & 108 & 1.08 & 54.75 & 0.91 & Shear \\
\hline & 13 & & 50.7 & 67 & $\mathrm{~N}$ & 180 & 177 & 0.98 & 55.95 & 0.89 & Shear \\
\hline
\end{tabular}

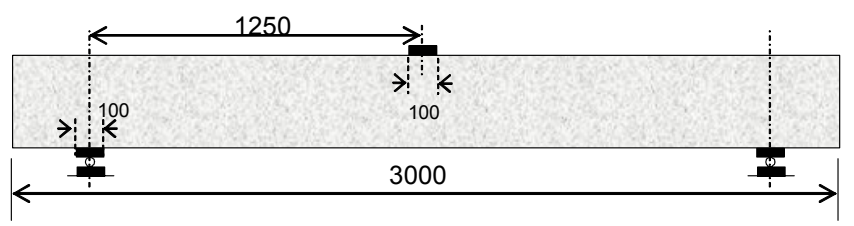

Loading set-up for beam (1)
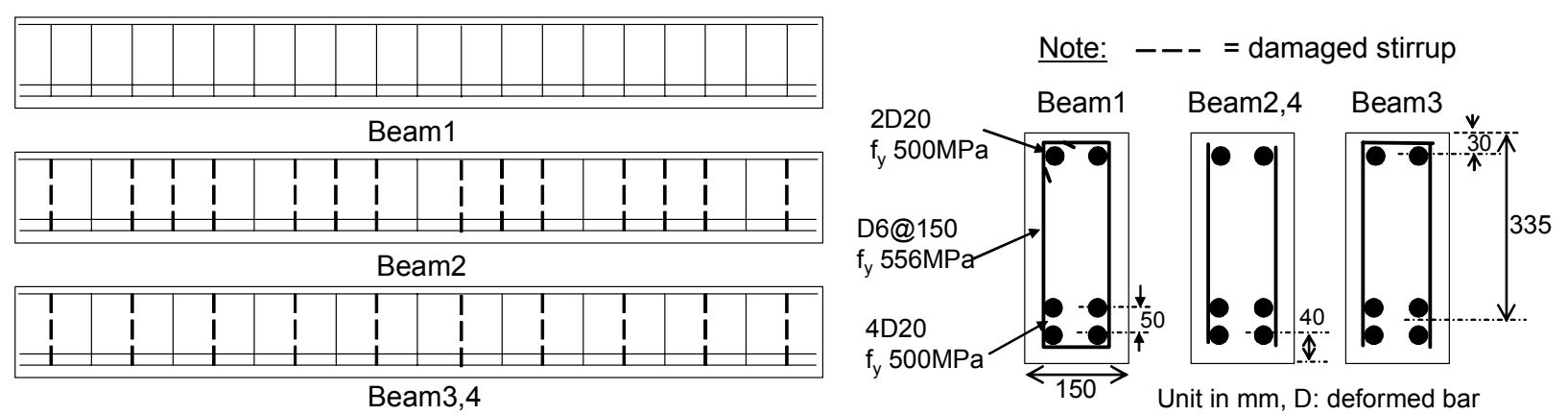

Fig. 10 Specimen set-up and dimension for group A: Beams (1), (2), (3) and (4). 
stirrups were intentionally fabricated by straight reinforcement without hook in both the top portion near the compressive bars and the bottom near the tensile bars to simulate the broken web reinforcement, except for beam (3) where defective stirrups were an inversed U-shaped with the straight edge of the main reinforcement.

A systematic analysis was conducted by applying the same approach for the bond deterioration zone as the previous analysis of the authors' experiment. The lack of concrete cover at the bottom of the beam was represented by assuming no tension stiffening (Okamura and Maekawa 1991) at the necked steel layers. Table 2 shows the analytical results along with the experimental ones. It can be seen that the analysis of the fractured web stirrups yielded the precise ultimate capacity along with consistent failure modes. Figure 14 shows the comparison of the experimental and FEM computed capacities. Numerically obtained cracking patterns at failure are illustrated in Figs. 15, 16, 17 and $\mathbf{1 8}$ for all four groups with different reinforcement arrangement and detail of defective stirrups.

In Group A, lower flexural capacity was produced compared with the potential strength in shear. Thus, the ultimate capacities of all defective stirrup beams were mostly the same as the referential one even though defective stirrups with insufficient anchorage were used. However, severe shear cracking damage was observed in Beam 2 containing the $75 \%$ defective web reinforcing bars, as shown in Fig. 15. The crack localization along the main reinforcement is characteristic like that in the experiment, as shown in Fig. 9. For Beam 3 and 4 containing 50\% defective stirrup (around only tension side for Beam 3 and both tension and compression sides for Beam4), both showed similar failure crack patterns to the reference beam, here the efficiency of the rest of non-defective stirrups was experimentally and numerically confirmed.

In Group B, the shear force carried by web reinforcement was approximately $50 \%$ of the concrete contribution when structural details were satisfied, and the

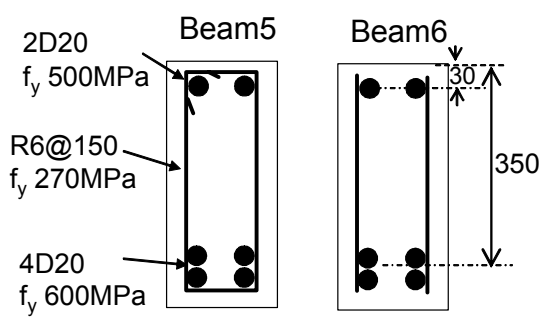

Unit in $\mathrm{mm}$, D: deformed bar, R: round bar

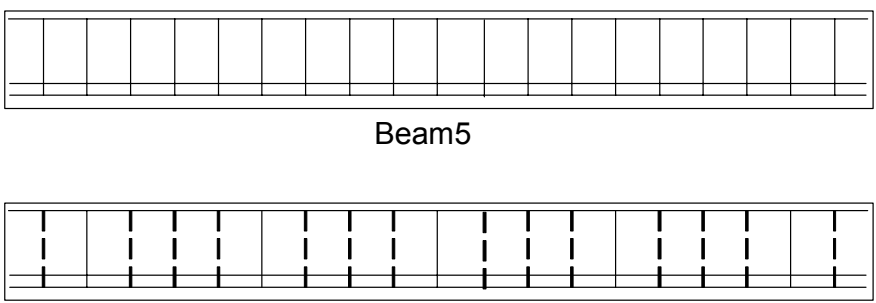

Beam6

Fig. 11 Specimen set-up and dimension for group B: Beams (5) and (6).

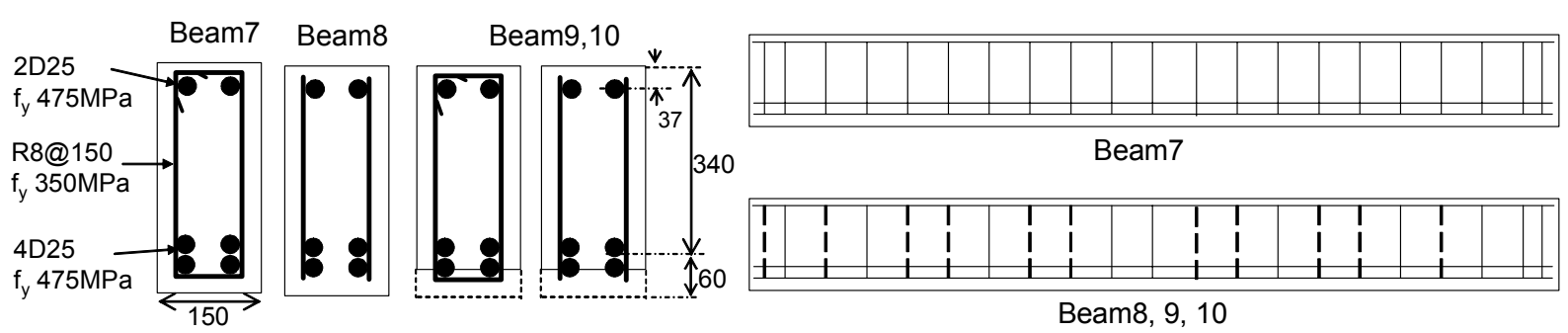

Fig. 12 Specimen set-up and dimension for group C: Beams (7), (8), (9) and (10).
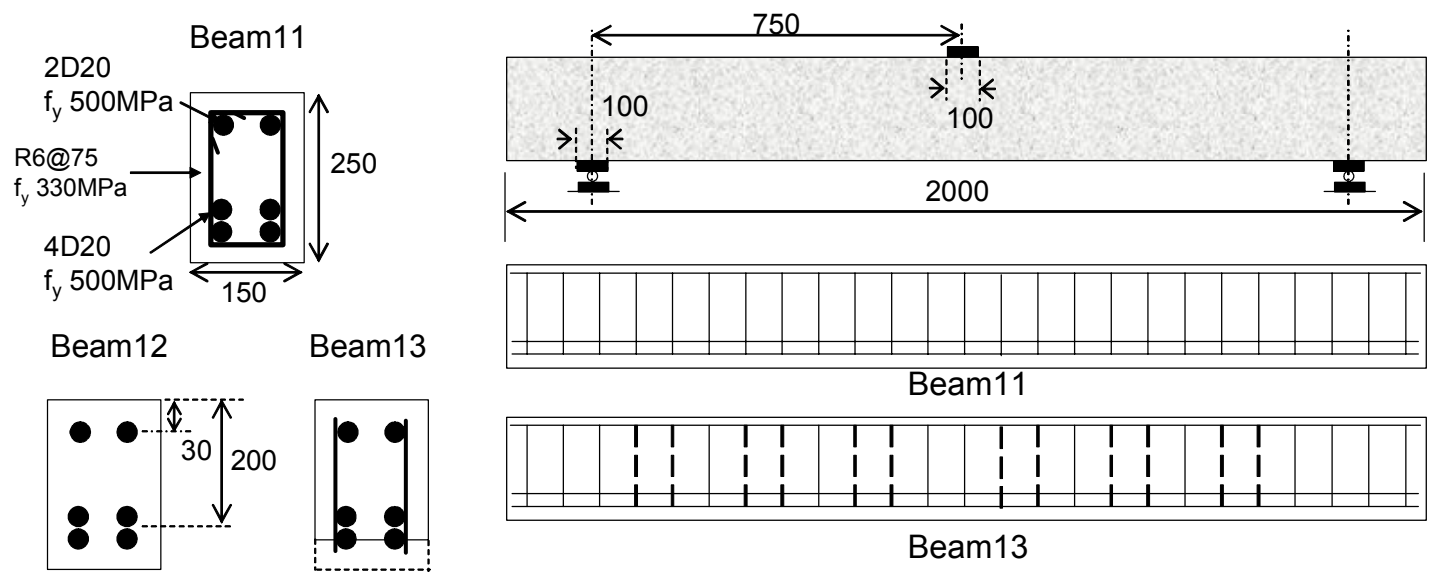

Beam13

Fig. 13 Specimen set-up and dimension for group D: Beams (11), (12) and (13). 
failure mode of the beams was originally in shear. Although, the FEM computation revealed small difference in failure crack patterns between the defective beams and the reference beam as shown in Fig. 16, the deterioration of the shear capacity was observed in the defective stirrup cases compared with the reference shear failure one. The numerical result considering the assumed bond deterioration at the extreme ends of stirrups was verified against the reasonably computed ultimate shear capacity.

Similarly, in Group C, the built-in damage of web re- inforcement resulted in the degradation of shear capacity compared with the reference shear failure beam, too. In Group C, the amount of web reinforcement was comparatively larger than in Group A. The effect of concrete cover spalling was also included in Beam 9 (no concrete cover along whole tensile steel) and Beam 10 (no concrete cover along tensile steel between supports). Figure 17 shows the numerical failure crack patterns with severe cracking damage around the defective areas where bond deterioration was placed. The effect of the concrete cover spalling beneath the main tensile steels

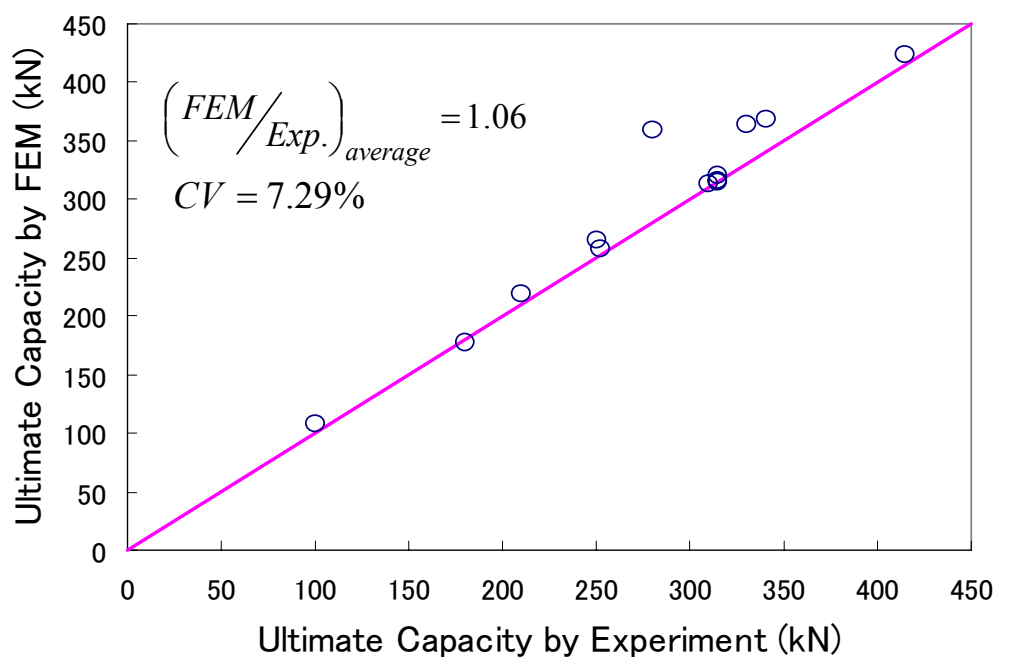

Fig. 14 Comparison between experimental result and FEM computed capacity.

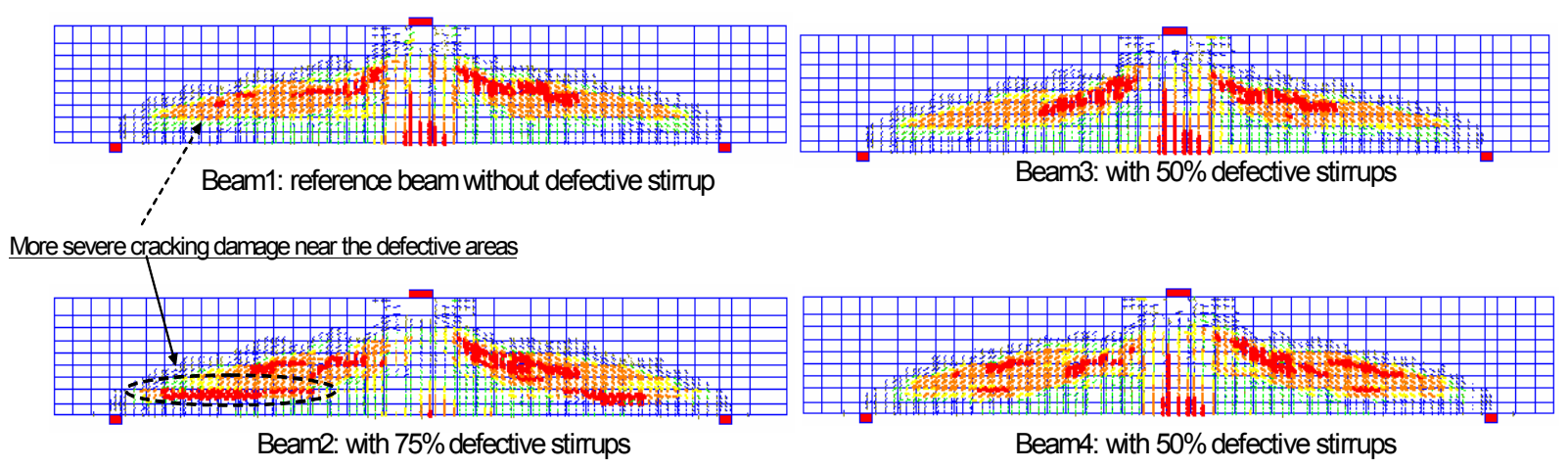

Fig. 15 Numerical crack pattern for group A- beams (1), (2), (3) and (4).

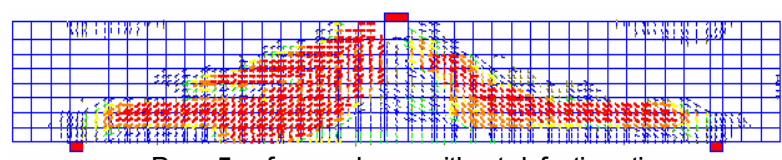

Beam5: reference beam without defective stirup

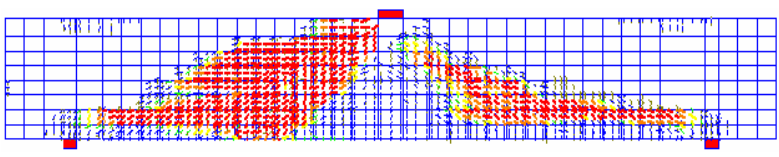

Beam6: with $50 \%$ defective stirrups

Fig. 16 Numerical crack pattern for group B- beams (5) and (6). 

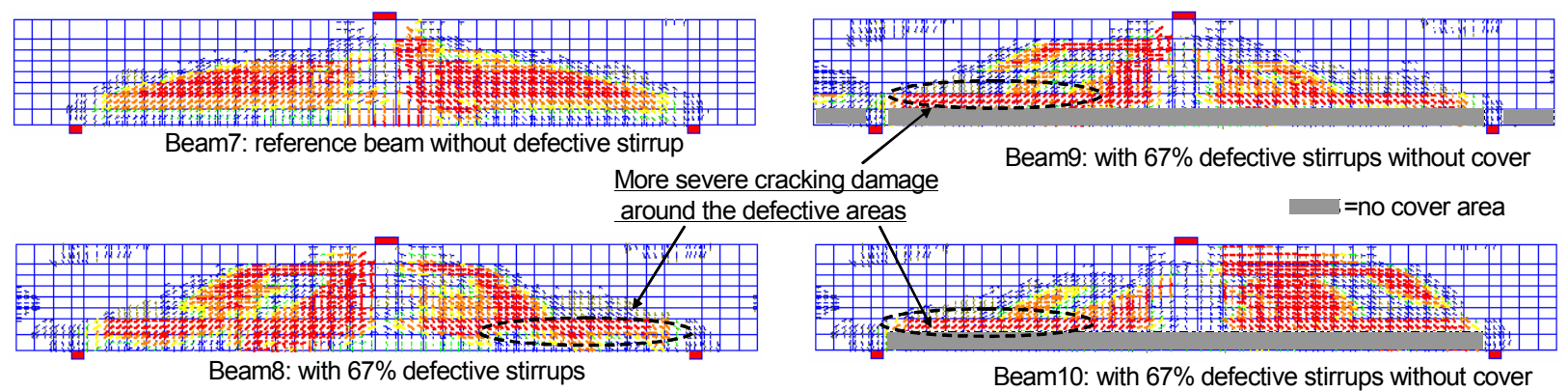

Fig. 17 Numerical crack pattern for group C- beams (7), (8), (9) and (10).
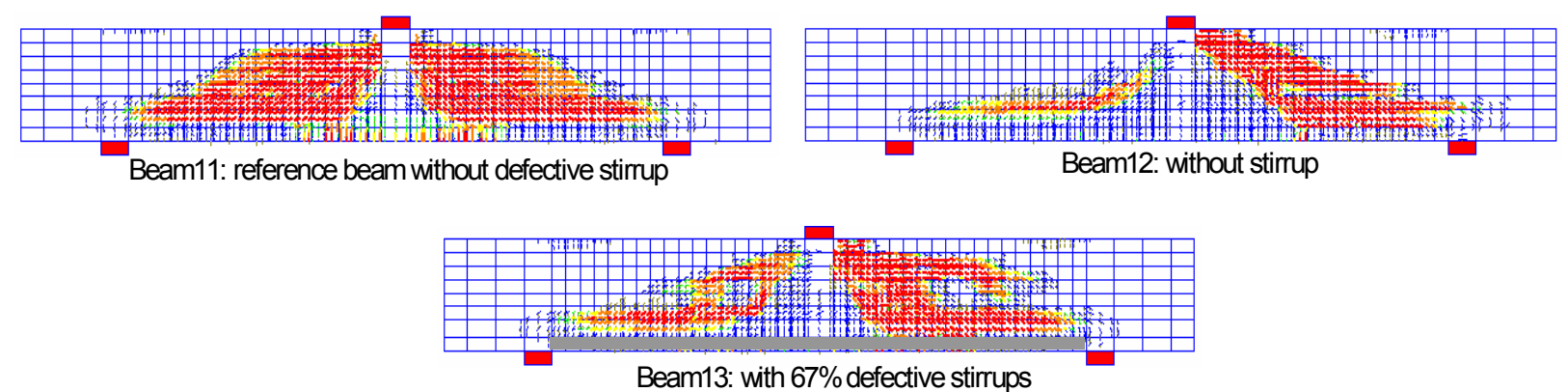

Beam13: with $67 \%$ defective stirrups

Fig. 18 Numerical crack pattern for group D- beams (11), (12) and (13).

was verified to be small in both the experiment and the simulation as the similar crack patterns were observed among Beam8, 9 and 10 in Fig.17. The numerical computed shear capacities were reasonably predicted by employing the assumed bond deterioration zones with no axial stiffness of reinforcement.

Group D provided the data for beams whose shear capacity carried by concrete is relatively smaller compared to group B and group C. Unlike the reference distributed shear crack, Beam11, the numerical crack reasonably captured localized diagonal shear crack for Beam12 containing no stirrup as shown in Fig.18. For Beam 13 containing $67 \%$ defective stirrups with no concrete cover along the tensile steels between supports, less distributed and more localized appearance of diagonal shear cracks was clearly seen similar to Beam 12 without stirrup as shown in Fig. 18. The effect of concrete cover was also small similar to Beam9 and 10 in Group $\mathrm{C}$ due to the bond deterioration of fractured stirrups at hook portions near the tensile reinforcements.

In all combinations, computational assessment of shear capacity was highly accurate, as shown in Fig. 14. Due to the remaining bond of stirrups placed around the anchorage zones of the main reinforcement, longitudinal anchorage (bond) failure was successfully prevented unlike in the authors' experiments with short development lengths with ruptured stirrups. As the tied-arch mechanism was firmly reproduced, the load carrying capacity of the concrete web was enhanced rather than the usual cases. On the other hand, the contribution of web reinforcement was moderated. As a whole, the total capacity is thought to have deteriorated accordingly.

\subsection{Experimental verification - Slender beam with comparatively smaller number of stirrups -}

As discussed in section 3.1, shear capacity of slender beams is much influenced by the damaged anchorage of stirrups. However, if the amount of web steel is moderate or small unlike the case discussed in section 3.1, the cracking pattern and load carrying mechanism of structural concrete are expected not to change much. Figure 19 shows the experimental results by Shioya, et. al (2002) with and without anchorage of stirrups. In this case, stirrups (denoted as No.1-without damage-) were provided by welding steel plates ahead of the stirrup ends. On the other hand, no hook was devised in the case of No. 3 and the extreme edge of the stirrups was situated at the level of the main reinforcement layer. The shear span to depth ratio was similar to the case described in section 3.1 but the shear fraction carried by the web steel was smaller compared with that of the concrete.

As shown in Fig. 19, crack patterns are not affected by the anchorage details and the reduction rate of shear capacity is comparatively smaller as expected. The proposed computational approach can satisfactorily capture the capacity and reversed cyclic characteristics of the beams with and without hook anchorage. In this postpeak analysis, two loading points are forced to move together. This implies no rotational degree of freedom on the constant moment span and similar damage is forced to develop in both shear spans after the peak. If we allow the rotational kinematics of the post-peak range in analysis, the damage in the structural softened states becomes unsymmetrical. As a matter of fact, the 
displacements at two loading points are not known from the literature but the mid-span vertical displacement is available. According to roughly symmetric experimental crack patterns as shown in Fig. 19, the authors assumed almost the same displacements developed at both loading points in the experiment, and applied this kinematics in the analysis.

The damaged beam experimentally and analytically exhibited a rather sharper drop in restoring forces in the softening stage. Two unloading/reloading paths were computed from different damage levels, as shown in Fig. 19. The capacity in the reversed paths is affected by the post-peak maximum displacement in computation. Analytical assessment of damaged RC members may yield reasonable or somewhat safe estimation.

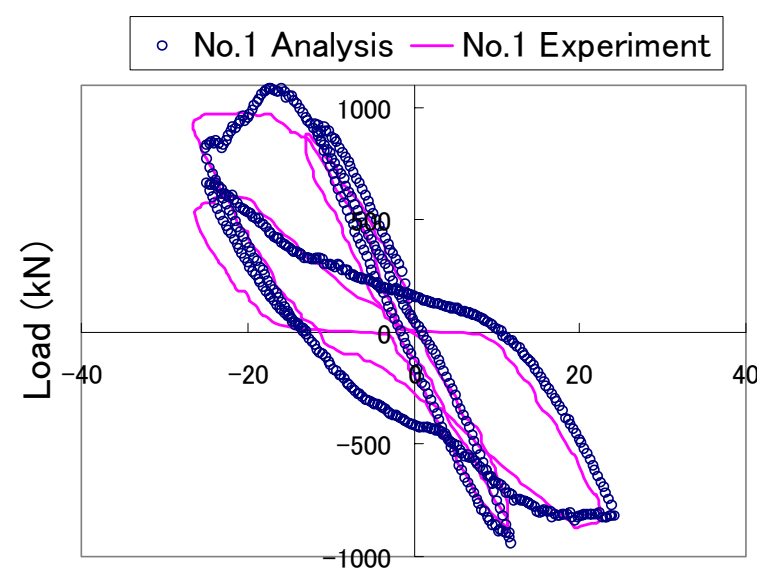

Mid span displacement ( $\mathrm{mm}$ )

\section{Size effect of fractured web reinforcement}

In the previous section, fracture of shear reinforcements inside RC beams was experimentally and numerically examined to have an adverse effect on the shear capacity. In the experiment conducted by the authors, important reduction in shear capacity of approximately $37 \%$ was observed in comparison with the non-damaged reference beam. In the experiment by Regan and Kennedy (2004), a relatively smaller reduction in shear capacity, up to $29 \%$ in Group D, was observed. By considering the bond deterioration zone of 10 times the fractured web steel diameter, the resultant shear capacity of the damaged beam with fractured web reinforcement can be well estimated, as explained in Chapter 3.

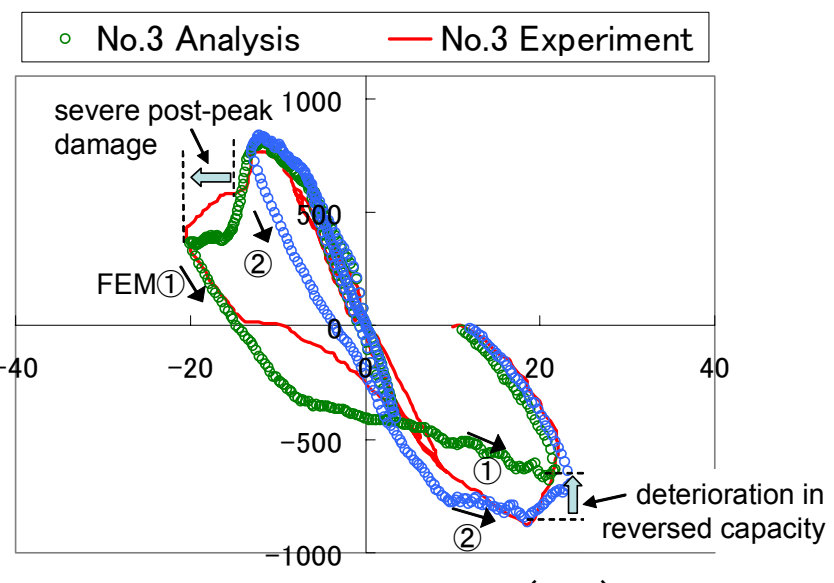

Mid span displacement ( $\mathrm{mm})$

No. 1
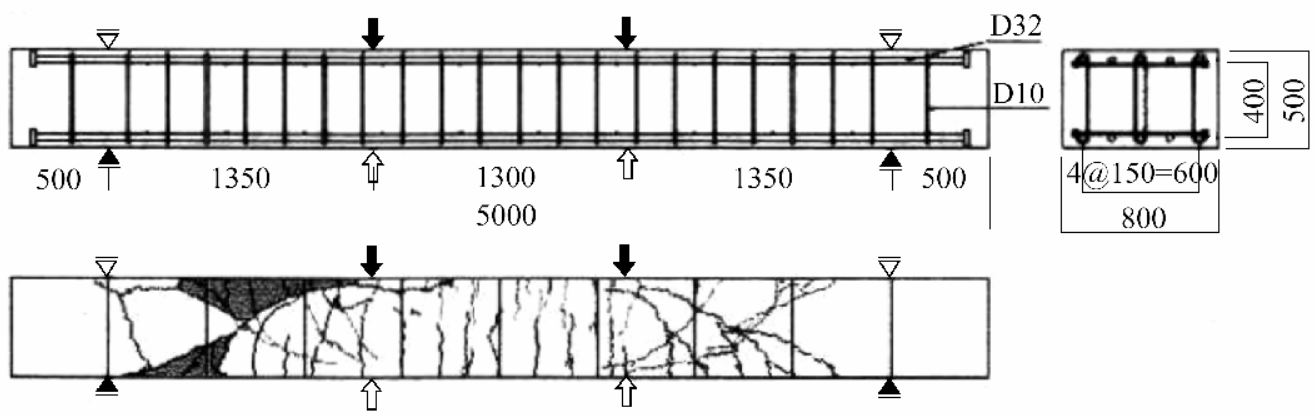

No. 3
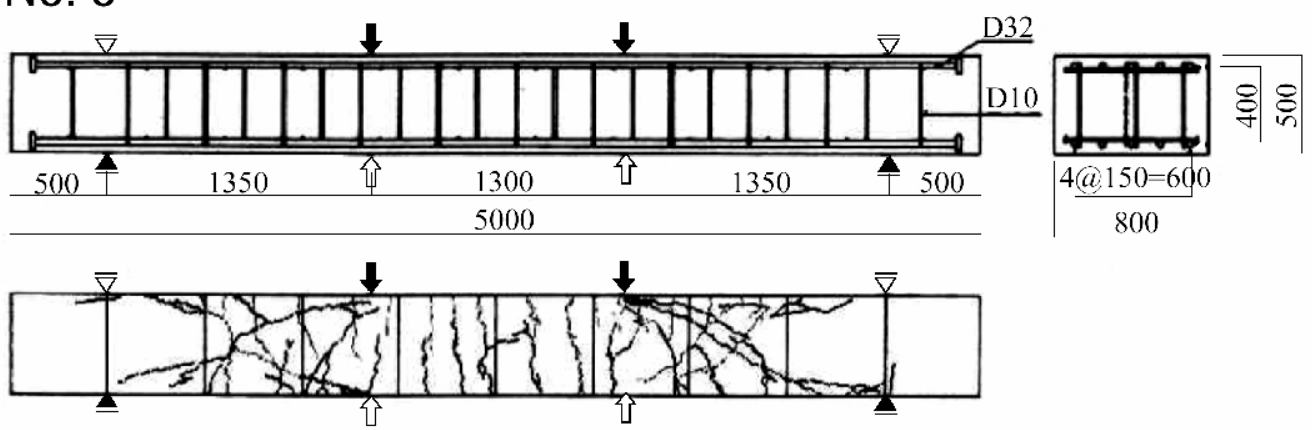

Fig. 19 Effect of stirrup rupture on the slender RC beam with comparatively smaller web steel. 
Here, real sized RC members will be discussed. The dimensions of real scale structures may be several times larger than those of the laboratory specimens. Due to limitations of fabrication using the discretized bar sizes available in industry, the diameters of reinforcing bars cannot be proportionally coordinated with the sizes of members. Thus, detailed reinforcement arrangement such as multiple layers of steel in real structures is usually required when the same reinforcement ratio is maintained. Figure 20 shows an example of an RC section in the authors' experiment and the assumed large sized RC in the scale of actual members in service. Both sections have the same reinforcement ratio for the main and shear directions and the same material properties of steel and concrete, as shown in Table 1. With the same fractured web reinforcement legs at the bent portion near tensile reinforcement, the extent of assumed bond deterioration of the 10 times web reinforcement diameter in the small RC section is located beyond the reinforcement layers, while in the large beam, the bond deterioration zone remains in the reinforcement layers.

Figure 21 shows the comparison in the degradation of shear capacity of the non-damaged reference beam and the fractured web reinforcement beam for the laboratory size and the large one of the real $\mathrm{RC}$ section. Less reduction in shear capacity of $16 \%$ compared with the non-damaged beam was observed in the case of the large sized RC beam where multi-layers of reinforcement arrangement are demanded in practice. This results in the bond deterioration zone being located within the main steel layers. Although both sections have the same structural and material properties with the same shear span to effective depth ratio, the effect of fractured shear reinforcement on the shear capacity degradation does not linearly vary in dimension. Consequently, this size effect will be realized and considered carefully when dealing with shear capacity assessment of the fractured web reinforcement beam in the real scale of $\mathrm{RC}$ members.

\section{Conclusions}

The influence of fractured web reinforcement in $\mathrm{RC}$ beams was investigated by experimental and analytical

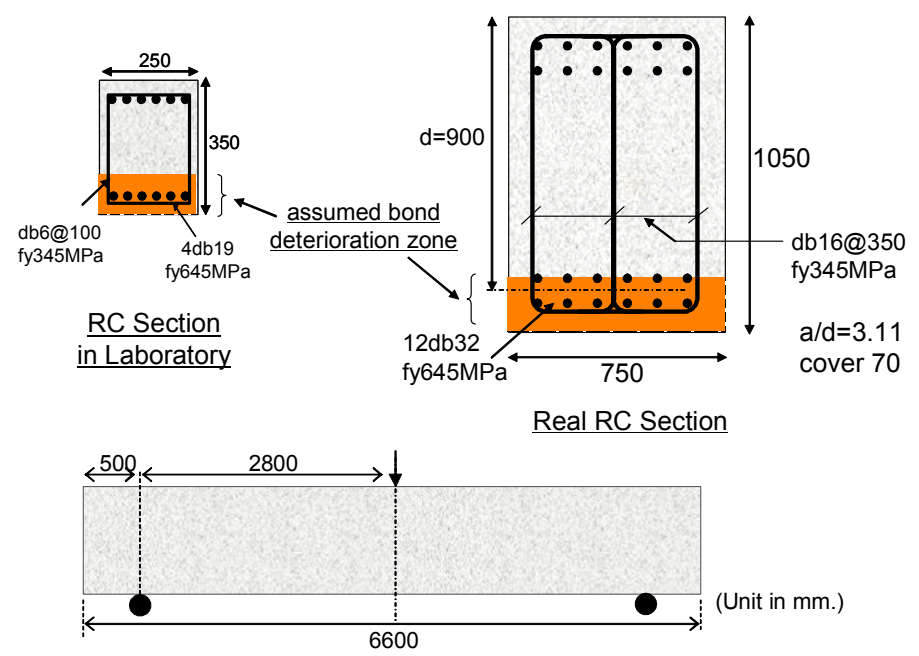

Fig. 20 The comparison of RC section in laboratory and the real design.
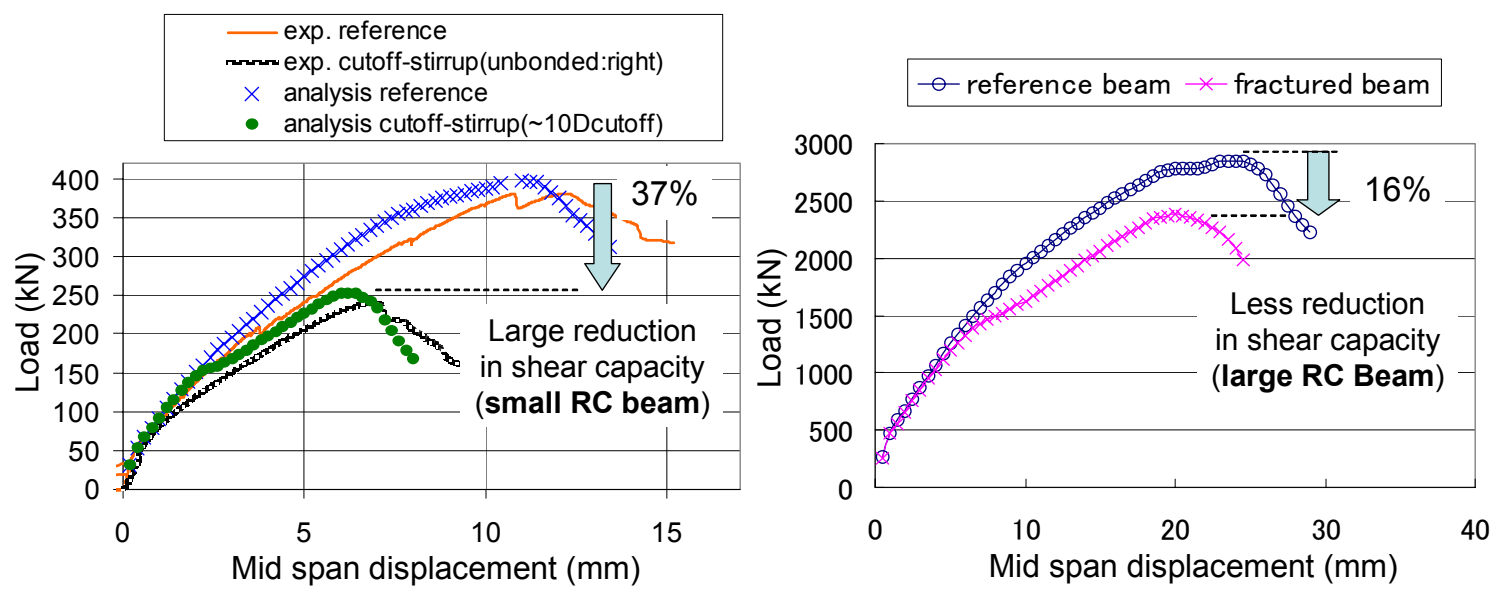

Fig. 21 Size effect in reinforcement of RC member with fractured shear reinforcement. 
means. As a mock-up of stirrups broken by corrosion or alkali-aggregate reaction, shear reinforcing steel bars were fabricated without hook anchorage. The effect of locally damaged bond near the fractured steel portion was also discussed in the experiment by wrapping vinyl tape at the straight edges of the fractured stirrups. From the experimental results and analysis, the following conclusions can be drawn.

(1)When anchorage of web reinforcement by hooks is not provided, longitudinal cracking along the main reinforcement, where the unprocessed straight edges lie, takes place and was verified experimentally. In this experiment, after longitudinal cracks developed, shear reinforcement could hardly function effectively to yielding. Instead, a tied arch action was newly created in the load carrying mechanism of web concrete, leading to possible failure of anchorage of the main steel.

(2)Non-linear finite element analysis was confirmed as an efficient tool for computational performance assessment of damaged beams with broken stirrups of no anchorage, by considering the bond deterioration zone of ten times the diameter of the stirrup steel bar. The shear reinforcement is assumed not to work anymore just in this bond deterioration zone even after cracks intersect with reinforcement.

(3) Verification of the assumed bond deterioration zone as in (2) was first made through analysis of the authors' experiments. The numerical results show fair agreement with the experimental facts both in terms of loaddeflection responses and failure crack patterns. The computed localized cracking along the main reinforcement was successfully reproduced as in the experiment. Further verification of the non-linear analysis with proposed assumed bond deterioration zone was performed by the simulation of other experimental results from the literature. By applying the assumed bond deterioration at the fractured zones, satisfactory simulation by computational approach was achieved.

(4)The size effect of the stirrup damage in RC members was discussed from a practical viewpoint. Due the limited number of available sizes of reinforcing bars in industry and their efficient fabrication, reinforcing bar diameters and cross sectional dimensions cannot be proportionally specified in accordance with the size of members. Consequently, the assumed bond deterioration zone in real RC members of large size may be located inside the zone of multi-layered reinforcement. Hence, the effect of fractured web steel on shear capacity is found computationally to be less harmful compared with the scaled-down RC members in laboratory.

\section{Acknowledgements}

The authors appreciate their fruitful discussion with Dr. T. Ishida and Dr. T. Kishi of The University of Tokyo. This study was financially supported by Grant-in-Aid for Scientific Research (S) No. 15106008.

\section{References}

Igarashi, S. (2005). "Effect of ductile reinforcement covering surface of member." Proceeding of JCI, 24 (2), 1273-78.

Japan Society of Civil Engineers (2004). "Standard Specification for Design and Construction of Concrete Structures." (English version of Structural Performance Verification ).

Mishima, T., Yamada, K. and Maekawa, K. (1992). "Localized deformational behavior of a crack in RC plates subjected to reversed cyclic loads." Proc. of JSCE, V-16 (442), 161-70.

Miyagawa, T. (2003). "Safety evaluation of structures with ruptured reinforcing bars by ASR (intermediate report)." Journal of JSCE, 88, 83-84.

Maekawa, K., Chaube, R. E. and Kishi, T. (1999). "Modeling of Concrete Performance." E \& FN SPON, London.

Maekawa, K. Kishi, T. and Ishida, T. (2003a). "Multiscale modeling of concrete performance - Integrated material and structural mechanics (invited)." Journal of Advanced Concrete Technology, 1 (2), 91-126.

Maekawa, K., Pimanmas, A. and Okamura, H. (2003b). "Nonlinear Mechanics of Reinforced Concrete." Spon Press, London.

Okamura, H. and Higai, T. (1980). "Proposed design equation for shear strength of reinforced concrete beams without web reinforcement." Proceedings of JSCE, 300, 131-41.

Okamura, H. and Maekawa, K. (1991). "Nonlinear Analysis and Constitutive Models of Reinforced Concrete." Gihodo Press, Tokyo.

Regan, P. E. and Kennedy Reid, I. L. (2004). "Shear strength of RC beams with defective stirrup anchorages." Magazine of Concrete Research, 56 (3), 159-66.

Shima, H., Chou L. L. and Okamura, H. (1987). "Micro and macro model for bond behaviour in RC." Journal of the Faculty of Engineering, The University of Tokyo (B), 39 (2), 133-94.

Shin, H., Maekawa, K. and Okamura, H. (1988). "Analytical approach of RC members subjected to reversed cyclic in-plane loading." Proceedings of JCI Colloquium on Ductility of Concrete Structures and its Evaluation, C2, 45-56.

Shioya, T., Higuchi, Y., Siokawa, H. and Takagisi, M. (2001). "Flexural shear experiments of RC beams with T-headed bars as stirrups." Proc. of JCI, 23 (3), 799-804.

Toongoenthong, K. and Maekawa, K. (2004). "Interaction of pre-induced damages along main reinforcement and diagonal shear in RC members." Journal of Advanced Concrete Technology, 2 (3), 431-443. 